\title{
Effect of Respiratory Protection on Respiratory Flow Rates of Vehicle Spray Painters in Ibadan Metropolis, Oyo State, Nigeria
}

\author{
Akanbi OG1ㅗ Ismaila S01,2*, Nwosu $\mathrm{CK}^{1}$ and Oriolowo KT1 \\ ${ }^{1}$ Department of Industrial \& Production Engineering, University of Ibadan, Ibadan, \\ Oyo State, Nigeria \\ ${ }^{2}$ Department of Mechanical Engineering, University of Abeokuta, Abeokuta, Ogun \\ State, Nigeria
}

\section{Research Article \\ Volume 2 Issue 2}

Received Date: February 03, 2018

Published Date: March 16, 2018

DOI: $10.23880 /$ eoij-16000139

*Corresponding author: Salami Olasunkanmi Ismaila, Department of Mechanical Engineering, University of Abeokuta, Abeokuta, Ogun State, Nigeria, Tel: +234 8051449269; E-mail: ismailasalami@yahoo.com

\begin{abstract}
This study was carried out to determine the effect of insufficient respiratory protection on respiratory flow rates of vehicle spray painters.

Eighty-six vehicle body-spray painters were used for the research. The main instruments for data collection were the modified Health and Safety Washington States repair/spraying shops questionnaire. Peak flow meter (EN-13826 model) was used to determine respiration flow rates. The descriptive statistics were used to analyse the demographic characteristics of the participants while the inferential statistics of $t$-test was the tool used to test the significance at a level of 0.05 .

The values of peak expiratory flow rates (PEFR) before spray painting were significantly $(\mathrm{p}<0.001)$ higher than the values after spray painting. Moreover, the values of PEFR of spray painters were significantly $(p<0.001)$ lower than the values of the control group with an average of about $92 \mathrm{~L} / \mathrm{min}$.

The study concluded that the devices used by vehicle spray painters for respiratory protection were not effective. It was, therefore, recommended that the spray painters should use the recommended protective respiratory devices while working.
\end{abstract}

Keywords: Spray painters; PEFR; Nigeria; Health; Safety; PPE

\section{Introduction}

Application of paints is by a variety of processes including use of brushes, roller, dip, flow, conventional air spray, airless spray, disk spraying and powder coating [1]. In vehicle body repairs shop, general repairs on vehicles that have been damaged during accidents are undertaken to restore them to pre-accident condition [2]. Such general repairs include grinding the paint off the metal sheet, and applying, smoothing, shaping, and sanding polyester resin body fillers, which may expose technicians to toxic metals if the surface of the vehicle being repaired 


\section{Ergonomics International Journal}

has lead, cadmium or chromium [3] after which the vehicles are spray painted. Spray painting process exposes spray painters to hazardous particulates and vapours [4]. Paint in vehicle body repair is polyurethanebased owing to their outstanding technical features such as durability, colour stability, and resistance to abrasion, chemicals and weather extremes [5]. These vehicle paints contain isocyanate to which spray painters are exposed [6,7]. Health and Safety Executive (HSE) [8] stated that breathing in isocyanate paint mist can cause asthma with the vehicle paint sprayers about 80 times more likely to get asthma than the average worker. It stated further that continued exposure to isocyanate could make asthma become permanent and severe. Liu, et al. [9] reported that isocyanate isa strong irritant and sensitizers with skin exposures leading to systemic respiratory sensitization, resulting in work-related asthma [10]. Abuelfadl, et al. [11] found clear associations among lung function parameters, CC16 serum levels, and exposures to isocyanate containing paint-sprays were demonstrated.

Similarly, Woskie, et al. [12] posited that long-term chronic exposures may lead to the lung and nervous system disorders, and to other health-related respiratory diseases. El Hamid Hassan, et al. [13] concluded that workers in the paint industry were at increased risk of several irritants and neuropsychological symptoms, which were significantly related to exposure to paint and organic solvents. Kamal and Malik [14] found that vehicle spray painters were exposed to isocyanate and aromatic solvents, which had significant effects on their hematopoiesis and they advocated for the need to create awareness among these workers to adopt self-safety measures during routine tasks. To minimize their exposure to volatile, organic compounds, vehicle spray painters should wear suitable types of respirators throughout the spraying process [15]. Depending on the hazardous and nature of the activity to be carried out, a range of respirators is available for consideration. The ranges of respirators in use, according to McCaughey [16] include filtering/dust mask, combined gas filter with an applicable face piece such as a mask or half mask and atmosphere-supplying respirator.

Filtering/dust mask respirators are used to reduce exposure to dust generated while sanding a vehicle, which is not to be used with gases, solvents, or vapours. The second type is the combined gas filter that is only used during exposures to specific chemicals or group of chemicals. It is used to reduce the concentration of contaminants in the workers' breathing zone. These combined gas filters are most often used during the priming process, although if primers present a potential overexposure to isocyanate, an air-supplied respirator may be needed. They stated that the third type, which is the atmosphere-supplying respirators supplied breathing air to the worker from a high-pressure compressor, a lowpressure ambient air pump, or by compressed air cylinders. They are used when applying chemicals with poor warning (i.e., odourless) characteristics or when concentrations exceed those that can be handled by other respirators. This suggestion was supported by OHSC [17] which stated that dust masks and combined gas filters fall under the category of air-purifying respirators as they contain filters to trap particles that are larger than the holes in the filter material or can absorb chemicals and has high capture efficiency [18]. The report by Occupational Health Safety Code (OHSC) [17] also categorized a range of combined gas filters available to absorb specific chemicals.

This study, therefore, examined the various respiratory protective devices (RPDs) used by the spray painters to identify whether there was any effect on the respiratory flow rates on workers in the auto body repair shops in Ibadan Metropolis.

\section{Materials and Methods}

\section{Population and Subject Selection}

Eighty-six (86) participants were selected from the vehicle the spray painters in Ibadan metropolis. Participants with a history of cigarettes smoking were exempted from the research. The purposive sampling technique was used to select that number of volunteer spray painters in the vehicle spray shops. The respondents from each location and establishment were selected, using the simple random sampling technique of $50 \%$ according to the workers available at the spray shops. This method was used to allow equal representation of all the spray painters in those shops and to generalise the results and conclusions. The researcher encountered difficulties while administering the questionnaire as some spray painters refused to disclose information about themselves while some who answered the questionnaire failed to undergo the respiration flow rate testing. Those who volunteered to provide information about themselves and undergo the respiration flow rates testing were seventy-seven.

\section{Instrument for Data Collection and Measuring Device}

\section{(i) Instrument}

The HSE collision repair questionnaire [8] was adopted and modified to reflect the characteristics of the population and the prevailing conditions in the area of 


\section{Ergonomics International Journal}

study, comprising 4 sections. Section A sought information on the demographic characteristics of the respondents while section $B$ tested their knowledge of occupational safety and health, availability, and utilization of RPDs and precautionary measures they use during spraying activities. Section C was elicited answers based on noticeable ailments during and after spraying. Last, section D sought to know the structure of the spraying booths, workplace and the various recommended or improvised protective devices used. Multiple answers were provided for the participants to choose from.

\section{(ii) Peak Flow Meter}

The peak flow meter (PFM) [EN 13826, Mini-Wright Flow meter, Clement Clarke International, U. K.] was the instrument used for measuring the peak expiratory flow rate (PEFR) of the participants. The instrument records the amount of air moving through the airways in the lungs over a specified period. It is one of the equipment used for conducting basic pulmonary function test as a preliminary test of the health condition for a patient lung. In addition, it is often used for finding the cause for shortness of breath, breathing difficulties and assessing the effects of contaminants on lung functions. The PEFR was chosen because it was the cheapest and easiest method in the identification and assessment of airflow limitations of people [19] and used in respiratory medicine due to the acceptability of its index of pulmonary function [20].

\section{Field Experiment Techniques}

The workers were informed about the aim of the study and that the data obtained would be used for scientific purposes only. An informed consent was obtained from all participants of this study while they were also given the right to refuse or participate in the study.

All respondents had the purpose, and the experimental procedure explained to them and adequate care was taken to ensure that the respondents fully understood the use of the PFM prior to every testing.

The pointer of the PFM was set at zero and the mouthpiece inserted into the meter. The PFM was held such that the fingers were clear off the scale and did not obstruct the holes at the ends. A separate mouthpiece was used along with the PFM for the individual subject.

The pulmonary functiontest was done as each subject took in a deep breath, put the mouthpiece of the PFM into the mouth and close the lips around the mouthpiece. The subject took one breath, blew out hard and quickly until he emptied all the air from the lungs. Three trials were made for a subject and the highest reading was taken as the worker's PEFR.Two sets of readings were taken; the first was the pre-shift while the second was the post-shift of the same day.

\section{Period of Study}

The research lasted for six (6) weeks with a visit to all selected vehicle spray shops within Ibadan metropolis.

\section{Statistical Analysis}

Data obtained from the field were analysed using descriptive and inferential statistical techniques. The descriptive techniques used were frequencies and simple percentages, means and standard deviation; while the $t$ test was the inferential tools used. The formulated hypotheses were analysed using SPSS 17 version for Windows.

\section{Results}

This study was carried out to assess the effect of insufficient respiratory protection on respiratory flow rates of car spray painters in the Ibadan metropolis.

\section{Population and Subject Selection}

Four respondents (4.7\%) were between 16 and 20 years while $38(44.2 \%)$ were between 31 and 40 years. Twenty-eight $(32.5 \%)$ of the respondents were between 21 and 30 years, whereas $16(18.6 \%)$ painters were 41 years and above.

Fifty-three (61.63\%) of the respondents attended secondary school while 26 (30.23\%) attended only primary school and 7 (8.14\%) attended technical schools.

Forty $(46.51 \%)$ of the respondents had $11-16$ years' experience on the job while $30(34.88 \%)$ had an experience of 6-10 years on the job. Fourteen $(16.27 \%)$ of the respondents had been on the job for 21 years and above while $2(2.33 \%)$ could be young apprentices on the job with less than 2 years' experience.

\section{Types of Respirators Used While Spraying}

Twenty-five $(29.1 \%)$ of the respondents used foam products to block their noses, $20(23.2 \%)$ used the handkerchief as respirators and $4(4.7 \%)$ used face towel while spraying. Respondents who used the disposable surgical face mask were $14(16.3 \%)$, whereas only 13 $(15.1 \%)$ and $10(11.6 \%)$ used filtering/dust mask and combined gas filters, respectively. This result implied that only $23(26.7 \%)$ use the recommended RPDs and none of 


\section{Ergonomics International Journal}

the spray painters visited had the atmosphere-supplying respirator.

\section{Availability of the Recommended Respirators in the Market}

Sixty-seven $(77.9 \%)$ of the respondents knew that recommended respirators were available in the market while $19(22.1 \%)$ responded that they were unaware of the availability of the recommended RPDs in the market. This implied that their level of education could be an important contributory factor. In a confirmatory market survey carried out by the researchers, it was established that the recommended RPDs were available in the market at an affordable price to the spray painters ranging from $\$ 100.00$ to $\$ 750.00$ (EUR $100=\$ 36720$; USD $100=$ \#30585).

\section{Attendance at Health and Safety Training}

The respondents who have attended any form of a training about health and safety precautions in using protective devices on the job were $60(69.8 \%)$ while 26 $(30.2 \%)$ have attended no form of such programmes. The apprenticeship status of these $26(30.2 \%)$ and level of education, might have caused the non-attendance of health and safety training.

Table 1 presents the descriptive statistics of PEFR of spray painters before and after painting and for the control group. The $5^{\text {th }}, 25^{\text {th }}, 75^{\text {th }}$ and $95^{\text {th }}$ percentiles of the PEFR for spray painters before and after painting and for the control group are also presented in Table 1. The values of PEFR before spray painting are significantly higher $(p<0.001)$ than the values after spray painting with an average of about $28 \mathrm{~L} / \mathrm{min}$ over the period of taking the measurements. The values of PEFR of the control group are significantly higher $(p<0.001)$ than the values of spray painters after spray painting with an average of about $92 \mathrm{~L} / \mathrm{min}$. Figures 1 and 2 present a spray painter using the handkerchief and a spray painter using filtering/dust mask, respectively.

\begin{tabular}{|c|c|c|c|c|c|}
\hline Percentiles & $\begin{array}{c}\text { Spray Painter's PEFR } \\
\text { before work (L/min) }\end{array}$ & $\begin{array}{c}\text { Spray Painter's PEFR } \\
\text { after work (L/min) }\end{array}$ & $\begin{array}{c}\text { Control group } \\
\text { PEFR (L/min) }\end{array}$ & $\begin{array}{c}\text { \% reduction of } \\
\text { PEFR after work }\end{array}$ & $\begin{array}{c}\text { \% reduction of PEFR } \\
\text { over control group }\end{array}$ \\
\hline 5th & 288 & 259 & 400 & 2 & 1.8 \\
\hline 25th & 370 & 350 & 435 & 4 & 11 \\
\hline 75 th & 450 & 420 & 500 & 9 & 35 \\
\hline 95th & 502 & 481 & 553 & 14 & 78.9 \\
\hline M & 406.23 & 378.31 & 469.87 & 6.9 & 27.51 \\
\hline SEM & 7.52 & 7.12 & 5.09 & 0.42 & 2.62 \\
\hline SD & 65.98 & 62.5 & 44.68 & 3.66 & 22.98 \\
\hline Range & $250.00-550.00$ & $230.00-530.00$ & $390.00-580.00$ & $2.00-21.00$ & $5.00-97.00$ \\
\hline
\end{tabular}

Table 1: Descriptive statistics of peak flow expiratory flow rate (PEFR) of spray painters $(N=77)$ and control group $(N=$ 77).

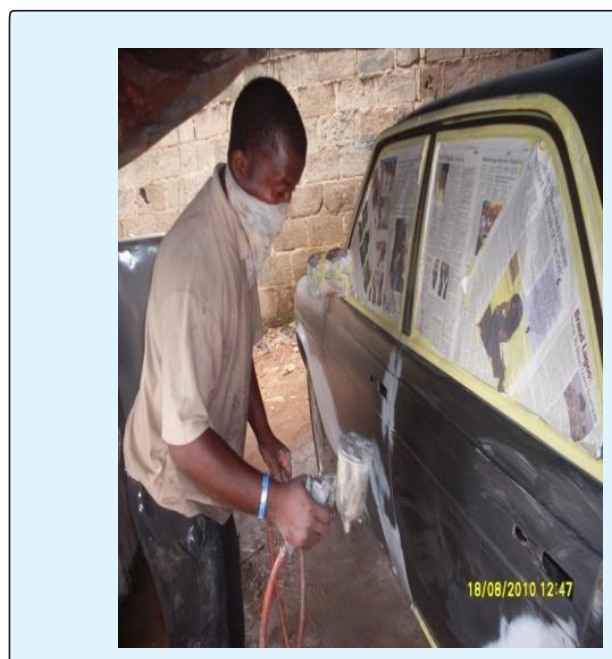

Figure 1: A spray painter using handkerchief.

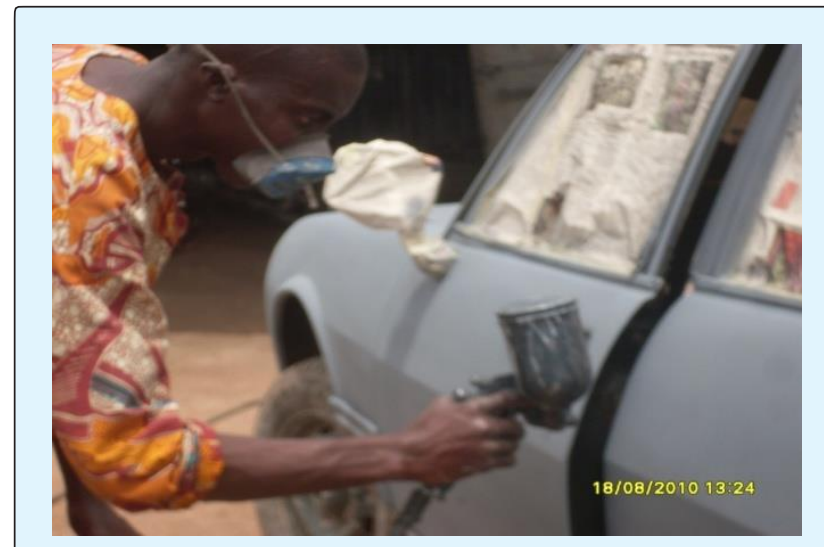

Figure 2: A spray painter using filtering/dust mask. 


\section{Ergonomics International Journal}

\section{Discussion}

Painters undergo surface preparation and pre-paint treatment. Pre-paint treatment process causes a crystallization to occur on the vehicle surface that provides improved paint adhesion and anti-corrosion protection. Automotive masking tape is used to cover areas that would not be painted. The vehicle bodies are then conveyed from this pre-paint treatment process to the prime-coat application process. After applying the primer, the coating is dried and sanded again. As the vehicle is ready for the prime-coating spray, sealers and other protective coatings (such as putty) are applied. After the sealers, putty and prime-coat applications, the first coat (base-coat) and the second coat (clear-coat) paints are applied to the vehicle by manually operated spray guns. The second coat application is followed by removing the masking tape, rinsing and wiping off with a soft dry cloth, thus completing the painting process.

During an in-depth inventory of equipment and facilities in the auto body repair shops, air-supplying respirators were not available while the available combination of filtering/dust mask and combined gas filters were 23 (26.7\%) and 63 (73.3\%) were improvised using either foam, handkerchief, face towel or disposable surgical face mask. This finding shows that there is a wide gap between the availability and non-utilization of the recommended RPDs for the vehicle body spray shops.

The improvised RPDs such as disposable surgical face mask, foam, face towels and handkerchiefs were in permanent use of spray painters, although the recommended respirators being available in the market. The non-utilization of recommended RPDs was reported by Sparer, et al. [21] who stated that spray painters did not always wear filtering/dust mask, combined gas filters and supplied air respirators in repair shops that made them available. They also stated that visits to the repair shops showed that some owners knew that the recommended respirators offer the best protection against isocyanate exposures but refused to wear them because of their perceptions about interference with visual acuity and mobility while spraying. Here, the findings show non-compliance with health and safety precautionary requirements, although 60 (69.8\%) respondents had attended health and safety training programme on spray painting in the past. Using unrecommended RPDs may subject the spray painters to respiratory-related ailments as Adei, et al. [22] found that about 79 percent of health complaints by paint sprayers in Ghana were respiratory related. The spray painters may also be subjected to chest/throat pains and headaches as Rongo, et al. [4] in a situational analysis of small-scale industry workers in Dar'es Salaam, Tanzania, found that 60.4 and $62.8 \%$ of painters self-reported chest/throat pains and headaches, respectively. Eifan, et al. [23] in their study of occupational asthma in 72 apprentice adolescent car painters concluded that an average of three years of working duration in an unfavourable/ unhealthy condition is sufficient for developing occupational asthma.

Sparer, et al.[21] also stated that isocyanate when used as catalysts, hardeners in two-part polyurethane in the final "clear coat" is recognized as being of principal concern and that when these products are sprayed, the aerosolised liquids can create a significant inhalation hazard for airborne isocyanate. Though spray painters were familiar with the health hazards related to working with isocyanate paints, they may not know that the nonusage of hand gloves would lead to dermal exposure to isocyanate, which could contribute to occupational asthma as noted by Ceballos, et al. [24]. Kamal and Malik [14] found that spray painting occupation had significantly higher mean corpuscle volume (MCV) and increased MCV may indicate the side effects on liver and that of pernicious anaemia [25] which may be due to an aromatic exposure in an occupational group. The reduction in PEFR of spray painters in this study agrees with the study of Rattray, et al. [10] that established a clear association among lung function parameters (Forced vital capacity, Forced Expiratory Volume in the first second and PEFR), CC16 serum levels, and exposure to isocyanate containing paint-spray which stresses the importance of regulation and control of such exposure.

This study has two main limitations; it lacked proper controls to attribute the difference in the PEFR strictly to painting and the number of subjects used in the study may not provide the basis to generalize the findings for the entire Ibadan Metropolis.

\section{Conclusion}

Vehicle body spray painters are highly susceptible to respiratory tract infections because of the exposure to the paints and their non-compliance with the prescribed health and safety precautions. The long years of work experience, most of the time, inform the non-utilization of the RPDs even when they are available.

Safety in the auto body spray shops is important as the noticeable occupational ailments such as respiratoryrelated symptoms are due to exposure to the paints' constituents. The rate of exposure was high due to the long working hours and inhalation of the paints while 


\section{Ergonomics International Journal}

spraying can cause a serious health hazard if the recommended RPDs are not properly used.

Vehicle spray painters working in the auto body repair shops should be provided with training in the proper selection of recommended RPDs and its application.

\section{References}

1. El Mahdy NM, Radwan NM (2009) Assessment of Different Health Hazards in Painting Industry. Egypt J Occup Med 33(2): 211-232.

2. Best (2005) Automobile Body Repair Shops. Revision: September, 2000. Best's Loss Control Manual on CDROM, Version 2005.2 (2005).

3. Enander RT, Gute DM, Cohen HJ, Brown LC, Desmaris $\mathrm{AM}$, et al. (2002) Chemical characterization of sanding dust and methylene chloride usage in automotive refinishing: implications for occupational and environmental health. AIHA J 63(6): 741-749.

4. Rongo LMB, Barten F, Msamangal GI, Heederik D, Dolmans WM, et al. (2004) Occupational exposure and health problems in small-scale industry workers in Dar es Salaam, Tanzania: a situation analysis. Occup Med 54(1): 42-46.

5. Boutin M, Dufresne A, Ostiguy C, Lesage J (2006) Determination of air borne isocyanates generated during the thermal degradation of car paint in body repair shops. Ann Occup Hyg 50: 4385-4393.

6. Alexandersson R, Hedenstierna G, Plato N, KolmodinHedman B (1987) Exposure, lung function, and symptoms in car painters exposed to hexamethylendiisocyanate and biuret modified hexamethylendiisocyanate. Arch Environ Health 42(6): 367-373.

7. Pronk A, Preller L, Raulf-Heimsoth M, Jonkers IC, Lammers JW, et al. (2007) Respiratory symptoms, sensitization, and exposure response relationships in spray painters exposed to isocyanates. Am J Respir Crit Care Med 176(11): 1090-1097.

8. Health and Safety Executive (HSE) (2014) Safety in isocyanate paint spraying. 1-8.

9. Liu Y, Sparer J, Woskie SR, Cullen MR, Chung JS, et al. (2000) Qualitative Assessment of Isocyanate Skin exposure in auto body shops: A pilot study. Am J Ind Med 37(3): 265-274.
10. Rattray NJ, Botham PA, Hext PM, Woodcock DR, Fielding I, et al. (1994) Induction of respiratory hypersensitivity to diphenylmethane-4 4'diisocyanante (MDI) in guinea pigs. Influence of route of exposure. Toxicology 88(1-3): 15-30.

11. Abuelfadl AA, El-Ebiary AA, El-Maddah EI, Ibrahim S Ibrahim, Safinaz H El-Shourbagy (2010) Pulmonary Toxicity Among Car Spray Painters. Mansoura J Forensic Med ClinToxicol XVIII(1): 51- 64.

12. Woskie SR, Sparer J, Gore R, Stowe M, Bello D, et al. (2004) Determinants of Isocyanate exposures in auto body repair and refinishing shops. Ann Occup Hyg 48(5): 393-403.

13. El Hamid Hassan AA, El Moez Elnagar SA, El Tayeb IM, Sara Abd El Halim Bolbol (2013) Health Hazards of Solvents Exposure among Workers in Paint Industry. Open J Saf Sci Tech 3(4): 87-95.

14. Kamal A, Malik NR (2012) Hematological Evidence of Occupational Exposure to Chemicals and Other Factors among Auto-Repair Workers in Rawalpindi, Pakistan. Osong Public Health Res Perspect 3(4): 229238.

15. Jahangiri M, Adl J, Shahtaheri JS, Kakooe H, Rahimi Forushani A, et al. (2014) Air monitoring of aromatic hydrocarbons during automobile spray painting for developing change schedule of respirator cartridges. J Environ Health Sci Eng 12(41): 1-7.

16. McCaughey M (2017) Environmental/Occupational Health Compliance Certification Program Certification Workbook for Auto Body Repair Facilities. Auto Body Repair Certification Workbook. Rhode Island (US): Rhode Island Department of Environmental Management. 1-117.

17. Occupational Health and Safety Code (OHSC) 2009: 1568

18. Brown RC (1995) Protection Against Dust by Respirators. IntJ Occup Saf Ergon 1(1): 14-28.

19. Debray P, Shreevatsa BM, MG RB, Sen TK, Roy S, et al. (2008) A Comparative Study of the Peak Expiratory Flow Rate of Indian and Nepalese Young Adults in a Teaching Institute. J Nepal Med Assoc 47(169): 7-11.

20. Higgins B (1997) Peak expiratory flow variability in the general population. European Respiratory Journal 24: 45S-48S. 


\section{Ergonomics International Journal}

21. Sparer J, Stowe MH, Bello D, Liu Y, Gore RJ, et al. (2004) Isocyanate Exposures in Auto body Shop Work: The Spray Study. J Occup Environ Hyg 1(9): 570-581.

22. Adei E, Adei D, Osei-Bonsu S (2011) Assessment of Perception And Knowledge of Occupational Chemical Harzards, in The Kumasi Metropolitan Spray Painting Industry. Ghana J Sci Tech 31(2): 83-94.

23. Eifan AO, Derman O, Kanbur N, Sekerel BE, Kutluk T (2005) Occupational asthma in apprentice adolescent car painters. Pediattr Allergy Immunol 16(8): 662668.

24. Ceballos D, Reeb-Whitaker C, Glazer P, MurphyRobinson H, Yost M (2014) Understanding Factors That Influence Protective Glove Use Among Automotive Spray Painters. J Occup Environ Hyg 11(5): 306-313.

25. Hole JW (1992) Essentials of human anatomy and physiology. Dubuque, (IA): McGraw-Hill-Education. 